\title{
A Alienação Parental como Cosmologia Violenta
}

\section{Parental Alienation as Violent Cosmology}

\section{La Alienación Parental como Cosmología Violenta}

\author{
Bruna Barbieri Waquim* \\ Bruno Amaral Machado**
}

1 Introdução. 2 Cosmologias violentas pelas lentes de Ceretti e Natali. $3 \mathrm{O}$ fenômeno interdisciplinar da Alienação Parental. 4 Alienação Parental como uma cosmologia violenta. 5 Considerações finais. Referências.

\section{RESUMO}

Objetivo: $O$ presente artigo propõe debater as correlações possíveis entre o processo de Alienação Parental e o processo de violentização, a fim de explorar suas possíveis implicações teóricas, bem como conscientizar sobre os danos que a naturalização da primeira prática e a internalização dos seus efeitos podem causar ao público vulnerável de crianças e adolescentes.

Método: A partir da metodologia de levantamento bibliográfico e aplicação de questionário, busca-se explorar os conceitos trazidos pelo interacionismo radical (Athens),

\footnotetext{
* Doutora em Direito pelo CEUB. Mestre em Direito pela UFMA. Professora do Curso de Direito da Unidade de Ensino Superior Dom Bosco. Assessora Juridica no TJMA. Diretora cultural do IBDFAM/MA. São Luís, MA, BR. E-mail: <bu_barbieri@yahoo.com.br〉. https://orcid.org/0000-0001$5418-6160$

**Professor da graduação e dos Programas de Mestrado e Doutorado em Direito do Uniceub. Professor da FESMPDFT (Fundação Escola Superior do Ministério Público do Distrito Federal e Territórios). Professor colaborador da Escola Superior do MPU (Ministério Público da União) e do IDP (Instituto Brasiliense de Direito Público). Pesquisador associado do Nevis (Núcleo de Estudos da Violência - Departamento de Sociologia da Unb). Master Europeu Sistema Penal e Problemas Sociais e Doutor em Direito (especialidade Sociologia Jurídico-penal) pela Universidade de Barcelona. Estágio de pós-doutorado no Departamento de Sociologia da Universidade de Brasília, com estâncias de pesquisa em Fordham e John Jay, em 2011. Entre 2007 e 2012 foi professor do Programa de Doutorado em Ciências Penais da Universidade de San Carlos (Guatemala). Brasília, DF, BR. E-mail: <brunoamachado@hotmail.com>. http://orcid.org/0000-0002-7425-7066
} 
como comunidade-fantasma e violentização, na linha proposta por Ceretti e Lorenzo, com a prática da Alienação Parental descrita pela Lei brasileira no 12.318/2010.

Originalidade: A Alienação Parental foi expressamente descrita como violência psicológica no Brasil desde a promulgação da Lei no $13.431 / 2017$, porém não foram localizados trabalhos anteriores que tenham explorado o processo de violentização aqui apresentado na análise da Alienação Parental.

Resultados: A revisão bibliográfica empreendida evidenciou a proximidade entre o processo de violentização descrito por Athens com as consequências causadas pelo processo de Alienação Parental no âmbito intrafamiliar, por meio do qual uma criança ou adolescente apreende um referencial de comportamento abusivo que afetará sua vida adulta, o que foi sugerido por pesquisa empírica exploratória, apresentada no artigo.

Contribuições teóricas: $\mathrm{O}$ presente artigo reforça a natureza de situação de risco do ato de Alienação Parental. Além disso, amplia o leque da sua análise por parte das Instituições do Sistema da Justiça e demonstra a necessidade de que seja o tema inserido também no âmbito das Políticas Públicas no campo da família e da infância e juventude.

Contribuições: Dado que atualmente há campanha pela revogação da Lei de Alienação Parental, o artigo aponta para a necessidade de manutenção da Lei no $12.318 / 2010$, diante da demonstração do complexo fenômeno de violentização inserido nessa prática, com potencial de transmissão intergeracional.

Palavras-chave: Alienação Parental. Criança e Adolescente. Interacionismo simbólico. Violentização.

\section{ABSTRACT}

Objective: This article proposes to debate the possible correlations between the Parental Alienation process and the process of Violentization, in order to explore its possible theoretical implications as well as to raise awareness about the damage that the naturalization of the first practice and the internalization of its effects can cause to the vulnerable public of children and adolescents.

Method: Based on the methodology of bibliographic survey and questionnaire application, we seek to explore the concepts brought by radical interactionism (Athens), such as ghostcommunity and violence, along the lines proposed by Ceretti and Lorenzo, with the practice of Parental Alienation described by Brazilian Law No. 12.318/2010.

Originality: Parental Alienation has been expressly described as psychological violence in Brazil since the enactment of Law No. 13.431/2017, but previous works that have explored 
the process of Violentization presented here in the analysis of Parental Alienation were not found.

Results: The literature review carried out evidenced the proximity between the process of Violentization described by Athens and the consequences caused by the process of Parental Alienation within the family, through which a child or adolescent learns a reference of abusive behavior that will affect their adult life, which was suggested by exploratory empirical research, presented in the article.

Theoretical contributions: This article reinforces the risky nature of the act of Parental Alienation. In addition, it broadens the range of its analysis by the Institutions of the Justice System and demonstrates the need for the theme to be included in the scope of Public Policies in the field of family and children and youth.

Contributions: Given that there is currently a campaign for the repeal of the Parental Alienation Law, the article points to the need to maintain Law No. 12,318/2010, given the demonstration of the complex phenomenon of Violentization included in this practice, with potential for intergenerational transmission.

Keywords: Parental Alienation. Child and teenager. Symbolic interactionism. Violentization.

\section{RESUMEN}

Objetivo: El artículo pretende debatir las correlaciones posibles entre el proceso de Aliencación Parental y el proceso de violentización, con el objetivo de analizar sus implicaciones teóricas y esclarecer sobre los danos que la naturalización de la primera práctica y la internalización de sus efectos en el público vulnerable de crianzas y adolescentes.

Método: A partir de la metodología bibliográfica y la aplicación de cuestionarios, analiza los conceptos básicos del interaccionismo radical (Athens), como comunidad-fantasma y violentización, en los términos propuestos por Ceretti y Lorenzo, con la práctica de la Alienación Parental descrita por la Ley brasileña n 12.318/2010.

Originalidad: La Alienación Parental ha sido expresamente descrita como violencia psicológica en Brasil desde la promulgación de la Ley no 13.431/2017. Sin embargo, no hemos identificado investigaciones anteriores que hayan analizado el proceso de violentización en los análisis de la alienación parental.

Resultados: La revisión bibliográfica ha evidenciado las conexiones entre el proceso de violentización descrito por Athens con los efectos causados por el proceso de Alienación 
Parental en el ámbito familiar, a partir del cual una crianza o un adolescente aprehende un referente de comportamiento abusivo que afectará su vida adulta, lo que es sugerido por la investigación empírica exploratoria descrita en el artículo.

Contribuciones teóricas: El artículo refuerza la situación de riesgo del acto de Alienación Parental. Además, amplia las posibilidades del análisis por las instituciones del sistema de justicia y evidencia la necesidad de que el tema sea inscripto en el ámbito de las Políticas Públicas en el campo da familia y de la infancia y la juventud.

Contribuciones: Como actualmente hay una campaña por la revocación de la Ley de la Alienación Parental, el artículo destaca la necesidad de preservación de la Ley $\mathrm{n}^{\circ}$ 12.318/2010, para enfrentar el complejo fenómeno de la violentización referido a esa práctica, con potencial de transmisión intergeneracional.

Palabras-clave: Alienación Parental. Crianza y Adolescente. Interaccionismo simbólico. Violentización.

\section{INTRODUÇÃO}

A violência é um fenômeno complexo que ocupa a agenda de distintos campos de pesquisa. A tarefa de defini-la, porém, constitui-se em desafio, tal a variedade de tipologias e sentidos que pode assumir. Além do desafio técnico da conceituação de um fenômeno tão diversificado e abrangente, some-se a isso o fato de que todos assumimos percepções próprias e particulares de violência, moldadas historicamente e segundo experiências e trajetórias vivenciadas por pessoas e grupos, o que explica por que atos e comportamentos sugerem graduação de reações tão diversas entre o que se considera agressivo.

A violência pode ser descrita como qualquer ação intencional, perpetrada por indivíduo, grupo, instituição, classes ou nações dirigida a outrem, que cause prejuízos, danos físicos, sociais, psicológicos e/ou espirituais; como relação social caracterizada pelo uso real ou virtual da coerção, que impede o reconhecimento do outro, pessoa, classe, gênero ou raça, mediante o uso da força ou da coerção, provocando algum tipo de dano; como o uso intencional da força ou do poder, real ou em ameaça, contra si próprio, contra outra pessoa ou contra um grupo ou uma comunidade, que resulte ou tenha possibilidade de resultar em lesão, morte, dano psicológico, deficiência de desenvolvimento ou privação (VIOLÊNCIA..., 2014).

Argumenta-se que parte das explicações sobre violência são facilmente constatadas. Outras estão profundamente enraizadas social e culturalmente. Pesquisas recentes sugerem que, enquanto fatores biológicos e vários fatores individuais explicam a predisposição para a 
agressão, com frequência, tais fatores interagem com fatores familiares, comunitários, culturais ou outros fatores externos, criando situações que podem deflagrar ações violentas (DAHLBERG; KRUG, 2006).

A Organização Mundial da Saúde - OMS indica três grandes categorias de violência, que correspondem às características daquele que comete o ato violento: a violência coletiva, que inclui os atos violentos que acontecem nos âmbitos macrossociais, políticos e econômicos e caracterizam a dominação de grupos e do Estado; a violência auto infligida, subdividida em comportamentos suicidas, e os auto abusos; e a violência interpessoal, subdividida em violência comunitária (a violência juvenil, os atos aleatórios de violência, o estupro e o ataque sexual por estranhos, bem como a violência em grupos institucionais) e a violência familiar (violência infligida pelo parceiro íntimo, abuso infantil e abuso contra os idosos). Parte dos estudos acrescentam a essa classificação a violência estrutural, que se refere aos processos sociais, políticos e econômicos que reproduzem a fome, a miséria e as desigualdades sociais, de gênero e etnia, violência essa que ocorre sem a consciência explícita dos sujeitos, mas que se perpetua nos processos sócio-históricos, naturaliza-se na cultura e gera privilégios e formas de dominação (VIOLÊNCIA..., 2014). Adverte-se, de outro lado, ainda que se estabeleçam as quatro categorias, eles se misturam e se entrelaçam de formas diversas (SILVA et al., 2007).

Critica-se, de outro lado, que, atualmente, embora a violência seja descrita como problema social, esta não encontra adequado canal de publicidade: não existe ainda lugar social e campo de intervenção e saberes que a reconheça como objeto próprio, como seu alvo de estudos e de atuação. Sem reconhecimento e definição como objeto de investigação científica, se tornam difíceis o relato e a exposição de suas distintas manifestações (SACRAMENTO; REZENDE, 2006). A crítica, contudo, deve ser problematizada em um contexto amplo que permita situar como a temática vem ocupando o campo de distintos saberes. A explicação dos atos violentos tornou-se objeto de disciplinas médicas (psiquiatria) e biocriminológicas que associam a violência a fatores que explicam a agressividade a partir de modelos biológicos ou biopsicológicos (WALBY; CARRIER, 2010, p. 275; EYSENCK, 1993, p. 91-105; JALAVA, 2006; SARNOFF; GABRIELLI; HUTCHINGS, 1993; SIMON, 1998).

No campo da sociocriminologia, a violência manifesta-se como ato desviado que foi objeto de intensa pesquisa desde o início do século XX, das teorias da desorganização social às teorias da associação diferencial e às teorias da anomia e as da subcultura (ANITUA, 2005; MACHADO, 2012), nas últimas décadas, retomadas e reformuladas pelas abordagens da aprendizagem social (AKERS, 1977) e pela teoria da eficácia coletiva (SAMPSON, 2012). 
No Brasil, o campo de estudos da sociologia da violência e da segurança pública tem importantes acúmulos de conhecimentos sobre a conflitualidade e as distintas dinâmicas violentas, um desafio para qualquer esforço de síntese da literatura produzida nos últimos anos. Entre os diferentes achados, aponta-se para a complexidade social e os processos que envolvem as sociabilidades violentas e as distintas representações sociais sobre a violência (PORTO, 1999; SILVA, 2004).

Esse extenso campo de saberes sobre a violência abre múltiplas possibilidades de análise. Para o objeto deste artigo, propomos recuperar, da tradição norte-americana, o interacionismo simbólico, abordagem bastante influente nas tradições sociocriminológicas, reinterpretada pelo interacionismo radical, para compreender os atos de violência. Ao contemplar as ações sociais, o interacionismo tem como ponto de partida as interações interpessoais mediante comunicações simbólicas, em que os significados das ações podem ser mantidos, modificados ou dados pelos atores, cujo self atua como mediador entre estes e a organização social, o interacionismo simbólico propicia categorias para compreensão de diferentes aspectos da vida social, no que se inclui o fenômeno da violência (BLUMER, 1969; CARVALHO, 2011).

Inspirados pelo interacionismo radical (ATHENS, 2013), "Cosmologias violentas: itinerários criminológicos”, Ceretti e Lorenzo (2015) se propõem a compreender o porquê de um ator, em um determinado contexto e um instante, decidir que deve recorrer à violência para resolver um cenário dramático. Pela via proposta por Athens (1992, 2013), partem do pressuposto de que o objeto "violência" não é um mero dado revelado, mas algo real, verdadeiro e objetivo dentro de um horizonte cognoscível e experimental, o que se torna melhor estudado a partir das lentes do interacionismo radical.

As reflexões de Ceretti e Lorenzo (2015) explicitam a necessidade de preservação das crianças e dos adolescentes quanto ao chamado "processo de violentização". Na linha interpretativa proposta, uma pessoa violenta "não nasce", mas sim "se faz". Sob essa ótica de que a violentização de uma pessoa é um longo e difícil processo, em que o ator da violência completa o ciclo e a vítima do processo passa a se comportar como um agressor desenfreado, como o sujeito que anteriormente a havia submetido à violência, os autores sugerem que a melhor fase para intervir contra a violentização é justamente no cenário do contexto familiar, inspirados também por argumentos da psicanálise, de que são as impressões e repercussões das relações educativas mantidas com os grupos primários (especialmente família) que formam a personalidade e permanecem de forma duradoura no indivíduo (CERETTI; LORENZO, 2015).

O objetivo deste artigo é aproximar a análise do fenômeno da Alienação Parental, descrito como violência psicológica contra crianças e adolescentes, às contribuições da 
identificação da violência como "cosmologia violenta", a fim de diálogos como conceitos como comunidade-fantasma e violentização com a prática da Alienação Parental objeto da Lei $\mathrm{n}^{\circ}$ 12.318/2010 no Brasil.

Para tanto, o presente estudo teórico vale-se da revisão bibliográfica para, a partir de pesquisa exploratória, propor análise crítica sobre o seu objeto, dividido em três seções: a primeira, destinada a extrair os principais marcos teóricos do interacionismo simbólico a partir do que propõem Mead, Blumer e do interacionismo radical, de Athens, particularmente retomado por Ceretti e Lorenzo; a segunda, voltada a discutir o fenômeno da Alienação Parental, a partir da interpretação sistêmica da Lei no 12.318/2010 e o Estatuto da Criança e do Adolescente; e a terceira busca estabelecer as inter-relações entre a prática de Alienação Parental e o fenômeno da violência pelas lentes do interacionismo radical e das cosmologias violentas. Pretende-se, assim, apresentar novas possibilidades de reflexão sobre fenômeno complexo que ocupa juristas e psicólogos.

\section{COSMOLOGIAS VIOLENTAS PELAS LENTES DE CERETTI E NATALI}

O interacionismo simbólico constitui-se em abordagem sociológica com foco na "compreensão do modo como os indivíduos interpretam os objetos e as outras pessoas com as quais interagem e como tal processo de interpretação conduz o comportamento individual em situações específicas" (CARVALHO; BORGES; REGO, 2010, online). Embora exista debate sobre as origens do interacionismo simbólico, há consenso de que George Herbert Mead e Herbert Blumer estão entre os pioneiros entre os interacionistas.

Mead, psicólogo cuja trajetória acadêmica no campo da filosofia consolidou-se em forte intersecção com a sociologia e a psicologia social, sustentava que a sociedade participava diretamente na construção do "self", pois a forma como o indivíduo concebia seu lugar no mundo, seus limites e possibilidades, se dava em relação com o "outro generalizado". A psicologia social deveria assumir ares "realistas", na medida em que, para Mead, as experiências humanas deveriam ser buscadas a partir dos significados conferidos aos atos. $\mathrm{O}$ foco de análise deveria se dar no modo como o indivíduo provoca as reações com seu parceiro de interação. A resposta sobre os significados estaria, portanto, na relação entre as fases internas e externas, ou seja, a mente como produto da relação entre organismo e situação. Mead propunha a vinculação entre a gênese do eu e a descoberta da sociedade: a criança descobre quem é ao aprender o que é a sociedade, o que ocorre essencialmente na interação com outros seres humanos. A identidade, assim, não seria préexistente, mas atribuída ao ser a partir de atos de reconhecimento social (MEAD, 1973). 
A partir do marco proposto por Mead e outras influências como Dewey, Park, Thomas, Cooley, Wirth, Znaniecki, entre outros filósofos e sociólogos norte-americanos expressamente referenciados, Blumer consolidou três pressupostos interacionistas: a) orientação dos atos do ser humano em função do que as coisas significam para ele; b) significado dessas coisas como consequência da interação social de cada um com seu próximo; c) significados são modificados pela interpretação das pessoas quando essas se defrontam com as coisas. Para Blumer, a vida social é, portanto, entendida como processo dinâmico de criação e recriação de significados, os quais não estão simplesmente dados pela realidade (BLUMER, 1969).

O interacionismo simbólico é problematizado por Athens naquilo que denominou de interacionismo radical, particularmente por enfatizar as relações de poder e de dominação nos grupos humanos, sobretudo quando se trata de operações veladas. Se as concepções interacionistas simbólicas, na forma como propostas por Mead e de Blumer entendiam que o exercício do poder se dá apenas por aqueles atores sociais que precisam competir pelo controle de um determinado ato social, Athens localiza o poder na integralidade dos atos sociais: também na cooperação social, o participante está sob dominação, mas, nesse caso, ele aceita a ordem, enquanto, no conflito, ele a rejeita ou a desafia (ATHENS, 1992, 2013).

$\mathrm{Na}$ proposta que escolhemos para diálogo neste artigo, o texto "Cosmologias violentas: itinerários criminológicos”, de Ceretti e Lorenzo (2015), alude à cosmologia como saber que estuda a estrutura, evolução e composição do universo (ROSENFELD, 2005). O termo "cosmologia" aplicado à noção de violência intenta dar sentido às ações humanas violentas, representando a invisibilidade característica dos fatores que conduzem ao gesto violento, à agressão. Os atores violentos são orientados por unicidade organizada em torno de uma comunidade-fantasma, conceito criado por Athens, que procura apoio moral nas respostas violentas, no que eles denominam de cosmologia violenta. Isso porque homem é um cosmo autocriado que confere sentido, e as deliberações reflexivas são atividades das quais o indivíduo é, em grande parte, consciente, das quais tomam parte os juízos, opiniões, elogios, admoestações de outros significativos internalizados (CERETTI; LORENZO, 2015).

Os indivíduos interpelam o mundo segundo os significados que este thes oferece, significados que se geram das interações sociais e se modificam e transformam por meio de processos interpretativos que intervêm quando cada indivíduo se relaciona com os signos que encontra. Esta é interação simbólica, pois, ao invés da comunicação dar-se diretamente entre os indivíduos (esquema "estímulo - resposta"), o indivíduo que recebe o estímulo (a reação do outro) e o interpreta, podendo escolher entre diferentes formas de resposta. Por 
isso, fortemente amparados no interacionismo radical de Athens, distinguem os conceitos de "eu" (impulso de atuar do organismo, seu sentido de liberdade e iniciativa), "mim" (a internalização das posições e comportamentos da sociedade) e "Self" (reflexividade, produto da atividade social do indivíduo), para tratar do "role-taking" (processo de interpretação) (CERETTI; LORENZO, 2015).

Da conversação entre "eu" e "mim" o indivíduo pode assumir-se como individualista (quando o "eu" prevalece sobre o "meu") ou conformista (quando o "mim" se destaca sobre o "eu”), ou seja, trata-se de procedimento contínuo de ação e reação em que os indivíduos controlam suas próprias condutas ao mesmo tempo em que sofrem o controle social. $\mathrm{O}$ processo é descrito nas metáforas do "play" (jogo puro e simples criado pelo próprio indivíduo para processar sua interação com os demais) e "game" (jogo mais organizado e complexo em que as atitudes do outro são levadas no cálculo das iniciativas do indivíduo) (CERETTI; LORENZO, 2015).

Athens vai de encontro à ideia de "role-taking" como interiorização das atitudes alheias, ao criar o conceito de "comunidade fantasma": um "parlamento" de pessoas reais ou imaginárias diante de cujas concepções o indivíduo tenta manter ou melhorar a sua própria reputação. A comunidade é "fantasma" para se contrapor à ideia da comunidade física em que o indivíduo se situa. É formada pelos "outros-significativos” que procedem de pessoas concretas que influenciaram a vida do indivíduo, como pais, amigos, etc., procedentes de diferentes épocas e experiências sociais, e cujas atitudes, após serem internalizadas na pessoa, viram "interlocutores fantasmas". Enquanto Mead entende o ato social enquanto socialidade, Athens o descreve como domínio. Se parte da literatura sociológica define domínio como relação social de supremacia ou superioridade, Athens sustenta que o domínio opera por meio da linguagem (ATHENS, 2013).

Athens identifica e sustenta as dinâmicas de criação dos criminosos violentos perigosos, com base na identificação e descrição do processo social que conduz ao desenvolvimento de uma comunidade-fantasma violenta, a que ele convencionou chamar de "violentização", estruturada em quatro estágios: brutalização [formada pelas subfases da submissão violenta (por coerção ou retaliação), horrorificação pessoal e adestramento violento], beligerância, atuação violenta ou enfrentamentos violentos por domínio e, por fim, a virulência. Esse processo de violentização apresenta circularidade, pois, quando o ator da violência completa o ciclo, a vítima indefesa da brutalização passa a se comportar como agressor desenfreado, como o sujeito que anteriormente havia rejeitado. Quando o "Self" do indivíduo se torna ultraviolento, produz-se a segregação, pois o "Self" se desprende dos pertencentes aos grupos primários, causando automarginalização dos grupos "benevolentes" e aproximação aos grupos "malevolentes" (ATHENS, 1992). 
Se, antes, a percepção da agressividade e violência resumia-se ao componente biológico, essa ideia foi aperfeiçoada até chegar-se ao componente psicopatológico de que a origem de um ato destrutivo é determinado por carência afetiva, daí porque muitos autores encontram como denominador comum a antissociabilidade / psicopatia o chamado "narcisismo" (CERETTI; LORENZO, 2015), que pode estar ligado a quatro modelos de patologias: patologias do sentimento de si, ligando-as aos quadros de paranoia e patologias borderline; as patologias do sentimento de autoestima, ligando-as às depressões; as patologias da indiscriminação do fantasiado e do real, ligando-as à eleição narcísica de objeto e às diversas funções que o objeto passa a ter na manutenção de um tênue equilíbrio psíquico no qual não há o reconhecimento da alteridade; as patologias do desinvestimento narcísico que correspondem ao não estabelecimento de certas funções do psiquismo ou de sua perda por excesso de sofrimento e que se ligam aos estados de vazio (BORACS, 2010).

Ceretti e Lorenzo (2015) concluem, então, que os atores violentos se orientam por unicidade organizada em torno de uma comunidade-fantasma que procura apoio moral nas respostas violentas, no que eles denominam de cosmologia violenta. Isso porque o indivíduo é um cosmo autocriado ao que é conferido sentido, e as deliberações reflexivas são atividades das quais o indivíduo é em grande parte consciente, e das quais tomam parte os juízos, as opiniões, os elogios, as admoestações de outros significativos internalizados.

Apresentados os conceitos centrais do interacionismo radical reinterpretado pelas cosmologias violentas (CERETTI; LORENZO, 2015), propomos, em seguida, discutir a partir dessa lente a Alienação Parental.

\section{O FENÔMENO INTERDISCIPLINAR DA ALIENAÇÃO PARENTAL}

O gênero "Alienação Parental" diz respeito a toda possibilidade de estranhamento, afastamento, distanciamento de um filho em relação a seu(s) genitor(es) e comporta uma subclassificação: a Alienação Parental Justificada ou a Alienação Parental Injustificada. Como exemplos de Alienação Parental Justificada, ou seja, em que existem reais motivos para que esse filho se afaste desse genitor, podem-se citar reais situações de negligência, maus-tratos, tratamento grosseiro, postura arbitrária, comportamento histérico, rigidez abusiva, ou até mesmo a passagem natural pelo estado da adolescência. São casos em que a Alienação Parental é justificada e provocada pelo próprio comportamento do genitor, do qual se afasta a criança ou adolescente como consequência natural dos atos praticados.

Por outro lado, o afastamento de um filho pode ocorrer de forma induzida, manipulada, fabricada, e por isso o nome Alienação Parental Injustificada, em que não existem reais motivos para esse distanciamento, e que é o objeto da Lei brasileira $n^{\circ}$ 
12.318/2010. Aqui, na Alienação Parental Injustificada, podemos enquadrar a Síndrome da Alienação Parental (como conjunto dos sintomas que uma criança ou adolescente eventualmente poderá desenvolver em virtude dessa indução de Alienação Parental Injustificada) e a Alienação Familiar Induzida (prática, por parte do adulto, de atos de interferência na convivência familiar de uma criança ou adolescente com um familiar que lhe seja significante).

Gardner foi pioneiro na teorização da chamada Síndrome da Alienação Parental SAP, distúrbio por ele identificado que atinge crianças e adolescentes expostos aos conflitos dos seus pais, no âmbito dos processos judiciais de disputa de guarda, e que representa verdadeira lavagem cerebral dos filhos em favor de um dos genitores. A SAP é por ele definida como perturbação em que as crianças são obcecadas com a depreciação e crítica de um genitor, uma vontade de denegrir que é injustificada e / ou exagerada, ressaltando que inclui não apenas fatores conscientes, mas subconscientes e inconscientes dentro do genitor que contribuem para a alienação da criança (GARDNER, 1999).

Distingue-se o conjunto de sintomas da criança ou adolescente alienado (Síndrome de Alienação Parental) do conjunto de atos praticados por um adulto visando à alienação dessa criança ou adolescente (Ato de Alienação Parental). O legislador brasileiro, ao se referir a esse problema, não traz na Lei no 12.318/2010 nenhuma referência sequer à Síndrome da Alienação Parental (conjunto de sintomas descrito por Gardner), mas a Lei se dirige ao Ato de Alienação Parental, enquanto comportamento de um adulto que viola direitos fundamentais de uma criança ou adolescente. É oportuno, porém, repensar o vocábulo usado pela lei, para substituir o termo "Parental" por "Familiar" e evitar a dita confusão recorrente entre a Síndrome de Alienação Parental (que não possui reconhecimento científico - ao menos ainda) e o Ato de Alienação Parental, que possui ampla comprovação de existência e potencial lesivo (WAQUIM, 2018; VERROCCHIO, et al., 2019; BAKER; DARNALL, 2006; BAKER, 2006), razão pela qual se defende o uso do termo "Alienação Familiar Induzida" (WAQUIM, 2018).

A Alienação Familiar Induzida pode ocorrer na forma de Alienação Parental Induzida (interferência na convivência entre genitores e filhos), mas também na forma de Alienação Avoenga Induzida (em que são os avós as vítimas dos atos de interferência), ou ainda Alienação Fraternal Induzida (em que os irmãos sofrem os atos de interferência convivencial), e tantas subclassificações quanto a dinâmica da vida real permita, a partir dos sujeitos passivos dos atos de alienação: se pais, irmãos, avós, padrastos, madrinhas, etc. (WAQUIM, 2018). Não obstante, o termo adotado pela legislação brasileira ainda é "Alienação Parental”, por força da expressa redação da Lei no 12.318/2010. 
A Alienação Parental é objeto de debate em distintos campos de saber, o que reforça a transdisciplinaridade do tema. No Serviço Social, a Alienação Parental é descrita como conjunto sistemático de atos que visa tanto dificultar ou impedir o convívio do filho com um dos seus genitores ou familiares quanto denegrir a imagem desse perante o filho e perante o contato social e institucional de referência da criança ou adolescente, com a finalidade de romper ou fragilizar o vínculo de parentalidade, entendido como relação de afeto, cuidados, referencialidade, entre outras dimensões (MONTAÑO, 2016).

Na Psicologia, a Alienação Parental é definida como tentativa de desqualificação do papel parental ou de seus parceiros ou da sua família extensa, por um dos genitores ou por pessoas ligadas afetivamente às crianças e adolescentes, criando impedimento para que eles convivam saudavelmente com os filhos (ARAUJO, 2017). Ocorre principalmente no contexto do litígio decorrente do divórcio, em que os conflitos do ex-casal acabam por envolver os filhos e principalmente filhos pequenos, quando o denominado alienador busca distorcer a imagem do outro genitor para a criança, tornando-o, para ele, um ser pouco cuidadoso, sem afeto, ou ainda abusador (CALÇADA, 2017).

No campo jurídico, identificamos conceitos de maior e menor precisão, como "processo consciente, ou não, desencadeado por um dos genitores - geralmente o guardião - para afastar a criança do outro" (DIAS, 2017, p. 24); a conduta praticada "por qualquer membro da família paterna ou materna (natural, extensa ou substituta) contra qualquer outro membro da família paterna ou materna [...] sejam eles unidos à criança por laços consanguíneos, afins ou socioafetivos" (MOLD, 2017, p. 230); e, ainda, "processo de esvaziamento da relação parental, com consequências maléficas ao desenvolvimento psíquico do filho, seja este criança ou adolescente” (MOREIRA, 2016, p. 49).

Dos conceitos acima apresentados, podemos definir a Alienação Familiar Induzida: agir voltado à finalidade de interferência injustificada na construção e manutenção do vínculo psicoemocional e convivencial entre uma criança ou adolescente e uma ou mais pessoas (familiar ou parente) que seja(m) a ela significante(s), realizada de forma consciente ou inconsciente por um adulto que, com essa prática, visa atingir aquele familiar ou parente, ainda que não pretenda expor aquela criança ou adolescente a qualquer risco mas que efetivamente expõe e a vulnera.

Uma das frentes de concretização da Proteção Integral envolve justamente colocar a salvo a criança e o adolescente de "qualquer forma de negligência, discriminação, exploração, violência, crueldade e opressão, punido na forma da lei qualquer atentado, por ação ou omissão, aos seus direitos fundamentais" (artigo 5o do ECA), o que alcança também o espaço da família. A Lei no 13.431/2017 inaugurou no ordenamento jurídico a 
confirmação de que o ato de Alienação Parental é uma forma de violência psicológica, o que atrai a necessidade de estabelecer mecanismos para sua prevenção e combate.

No estudo retrospectivo realizado por Ben-Ami e Baker (2012), foram examinados vários correlatos psicológicos de longo prazo de vivenciar Alienação Parental quando criança, definida como relato de que um dos pais tentou minar o relacionamento da criança com o outro. As diferenças entre aqueles que vivenciaram e não vivenciaram essa experiência foram medidas na autossuficiência e em quatro aspectos do bem-estar: abuso de álcool, depressão, apego e autoestima. Os resultados indicaram associações significativas entre a exposição percebida à alienação dos pais quando criança e menor autossuficiência, taxas mais altas de transtorno depressivo maior, menor autoestima e estilos de apego inseguro quando adultos. A conclusão das pesquisadoras sugere que existem associações psicológicas significativas de longo prazo na vida de adultos que sofreram Alienação Parental quando crianças.

No item seguinte, propomos novas vias para repensar a Alienação Parental a partir do processo de violentização, pela lente interacionista radical proposta por Ceretti e Lorenzo (2015).

\section{ALIENAÇÃO PARENTAL COMO UMA COSMOLOGIA VIOLENTA}

Como já exposto, o processo de "violentização" possui quatro estágios: brutalização [formada pelas subfases da submissão violenta (por coerção ou retaliação), horrorificação pessoal e adestramento violento], beligerância, atuação violenta ou enfrentamentos violentos por domínio e, por fim, a virulência.

O roteiro aplicado à prática de Alienação Parental permite inferir que o processo de alienização da criança ou do adolescente ocorre em dinâmicas que podem ser enquadradas ao esquema proposto: o familiar alienado, por meio da coerção ou retaliação, instala o sentimento de alinhamento patológico e promove verdadeiro adestramento do afeto e do raciocínio do infante, a fim de lograr êxito - ainda que esse não seja seu objetivo consciente - na brutalização e adestramento do afeto da criança ou adolescente.

Em estudo retrospectivo qualitativo realizado no outono de 2004, com 40 adultos que vivenciaram o problema da Alienação Parental quando crianças, Baker e Darnall (2006) intentaram examinar empiricamente e qualitativamente o fenômeno da Síndrome da Alienação Parental, partindo do conhecimento produzido por Gardner. Pretenderam identificar se existe população existente de pessoas que se identificam como tendo sido alienados de um dos pais devido a ações e atitudes do outro pai quando eram crianças e, 
em caso positivo, se era possível determinar se havia diferentes tipos de experiências de alienação parental ou se todos seguiram o mesmo esboço geral.

Baker e Darnall (2006) propõem que o conceito de "se tornar contra um pai devido ao comportamento e atitudes do outro genitor" ressoou como experiência real das pessoas entrevistadas. A partir de entrevistas, os pesquisadores sugerem três padrões de Alienação Parental: Mãe narcisista na família divorciada, descrita em 14 das 40 entrevistas, em que a manutenção da relação entre os participantes e seus pais, após o divórcio, era recebida como um abandono, uma perda e uma humilhação para essas mães, com possível diagnóstico de personalidade narcisística; Mãe narcisista na família não divorciada, descrita por 8 participantes da pesquisa, em que sequer houve o divórcio do casal, mas as mães alienantes atraíram os participantes em sua confiança de forma a solidificar seu relacionamento às custas do relacionamento com o pai alvo, usando técnicas como confidenciar à criança as falhas do pai; e o padrão de Genitor alienador frio, rejeitador e abusivo, descrito em 16 casos, em que a alienação ocorreu não por meio do pai alienante ganhando a criança através do encanto e da persuasão, mas por meio de uma campanha de medo, dor e denegrimento do pai alvo, além da imposição de violência física, verbal e/ou sexual às crianças.

Assim, o início do processo de violentização do filho alienado é a brutalização por ele sofrida a partir da submissão aos atos do familiar alienador, que nele incute uma resposta agressiva à figura do familiar alvo, passando essa resposta agressiva a orientar um comportamento cada vez mais prejudicial à harmonia da convivência familiar, de forma naturalizada. $O$ universo interno desse filho passa a agregar as experiências de alienação passadas, orientando suas novas escolhas de comportamento.

Coelho e Morais (2014), em revisão bibliográfica sobre as contribuições da Teoria Sistêmica acerca da Alienação Parental, apontam que autores de abordagem sistêmica há muito já observavam a existência de padrões transacionais recorrentes e cristalizados no relacionamento dos membros de um sistema familiar disfuncional, tais como relacionamento muito estreito ou de superenvolvimento; relacionamento fundido; relacionamento conflituoso; relacionamento vulnerável; relacionamento distante; rompimento; aliança; triangulação e coalizão; criança superprotegida; figura do "bode expiatório"; competição entre os pais; e coalizão cross-geracional. Em um processo de divórcio destrutivo, conflituoso e litigioso, em que os pais não conseguem separar o seu papel conjugal do parental, envolvendo os filhos em suas conflitivas e, nesse sentido, empreendendo a Alienação Parental, os membros do sistema familiar podem desenvolver alguns desses padrões de relacionamento transacionais (COELHO; MORAIS, 2014). 
Quando um dos pais estabelece um relacionamento super estreito com um dos filhos, a criança passa a ser uma extensão desse pai ou dessa mãe, compartilhando sentimentos de hostilidade, ódio e mágoa em relação ao outro par parental e manifestando uma percepção alterada da realidade. Um dos pais induz os filhos a enxergarem os fatos com as próprias lentes, formando um vínculo simbiótico com os filhos (vínculo que se baseia na relação de dois como um só e impede a autonomia e a independência de seus membros). Já no padrão relacional de aliança, um dos pais se alinha à criança, a qual se sente comprometida com esse genitor, estabelecendo com ele uma espécie de pacto de lealdade que não pode ser quebrado (COELHO; MORAIS, 2014).

A triangulação, por sua vez, ocorre em um sistema familiar quando os membros estão envolvidos, lutando em um conflito que não conseguem resolver automaticamente e tendem a trazer para dentro deste uma terceira pessoa; significa que, quando o casal parental vivencia de forma destrutiva seus conflitos, fazendo com que o sistema familiar atinja um pico elevado de ansiedade, uma terceira pessoa, no caso, o filho, é utilizado (ou triangulado) com o intuito de reduzir o nível de tensão do sistema, tornando-o mais tolerável. Geralmente, é em nome dessa criança que os pais se digladiam em juízo, pois é em nome do melhor interesse do filho que eles se mantêm ligados pelo conflito e se acusam mutuamente, razão pela qual a criança procurará, dessa forma, como um mecanismo de sobrevivência emocional, alinhar-se a um dos pares parentais (COELHO; MORAIS, 2014).

O padrão de competição entre os pais pela criança ocorre quando os pais competem pela lealdade do próprio filho, querendo que ele tome partido e escolha um dos lados para se alinhar. Nesse contexto, a criança é pressionada, de forma agressiva ou sedutora, a tomar partido no conflito conjugal de seus pais, e os pais impõem que o filho seja leal a um deles. No padrão coalizão cross-geracional rígida, os pais buscam formar um pacto especial de aliança com o filho, estabelecendo uma díade com a criança contra o outro par parental. Acredita-se que esse padrão relacional é o que mais se assemelha à descrição da Alienação Parental e é o mais prejudicial à subjetividade e à autonomia da criança (COELHO; MORAIS, 2014).

A fase seguinte do processo de violentização é a da beligerância, em que a vítima da violência, brutalizada, é obrigada a dirigir seu próprio Self a uma nova visão de mundo (CERETTI; LORENZO, 2015). Gardner (2002) sugeriu a ideia de que o filho alienado aparenta ser verdadeiro "pensador independente", pois, uma vez absorvida a campanha de difamação e agressão contra o familiar alienado, a criança ou adolescente passa a contribuir, pelas próprias vias, a essa campanha, como se seu parlamento interior fosse preenchido pelas percepções e noções do familiar alienador. Sua comunidade-fantasma, para usar as premissas do intervencionismo radical, é moldada pelas ações do familiar alienador, em 
interação com a criança/ adolescente, o que impacta o desenvolvimento de sua identidade e personalidade, pela ausência da dualidade e diversidade de contribuições.

Uma variedade de fatores situacionais também envolve as interações sociais entre o alienador e a criança/adolescente, como a criança que observa irmão sendo punido por demonstrar abertamente afeto em relação ao difamado pai, e que aprenderá rapidamente a não demonstrar tanto carinho, para escapar da mesma reprimenda. Da mesma forma, a criança que observa verbalmente o pai alienante ser verbalmente abusado pelo pai-alvo pode declarar autoprotetoramente preferência emocional pelo pai alienante (TURKAT, 2002).

A terceira fase do processo de violentização é a atuação violenta ou enfrentamentos violentos por domínio, em que o indivíduo se vê na oportunidade de praticar os atos violentos, pois a resolução violenta mitigada já foi internalizada (CERETTI; LORENZO, 2015). O estudo conduzido por Waquim (2020) sugere imagem que se aproxima do processo constitutivo da comunidade-fantasma que naturaliza a prática de atos de interferência familiar e o complexo de violência que envolve os atos de Alienação Parental. Em evento acadêmico na cidade de Tomar, em Portugal, em 23 de janeiro de 2020, no V Congresso Luso-brasileiro Alienação Parental: tutela integral da infância e juventude, Waquim indagou aos espectadores:

Figura 1 - Estado civil dos pais

Seus pais são separados / divorciados?

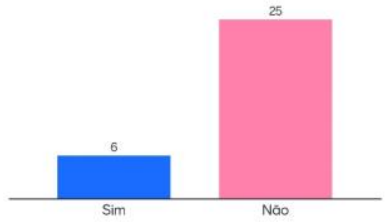

Fonte: (WAQUIM, 2020, p. 291).

O público majoritário, composto por profissionais das áreas do Direito e da Psicologia, brasileiros e portugueses, relatou que seus pais continuam em união conjugal.

Figura 2 - Relato sobre conflitos de lealdade

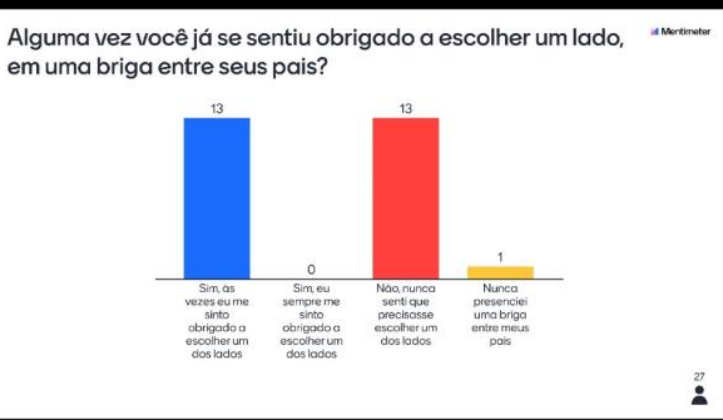

Fonte: (WAQUIM, 2020, p. 291). 
Praticamente metade do público participante relatou que já se sentiu inserido em conflitos de lealdade diante de briga dos seus genitores, o que significa que, dentre os 25 participantes filhos de pais que ainda mantêm relação conjugal, a percepção desse conflito existe em larga escala.

Figura 3 - Relato sobre falar mal

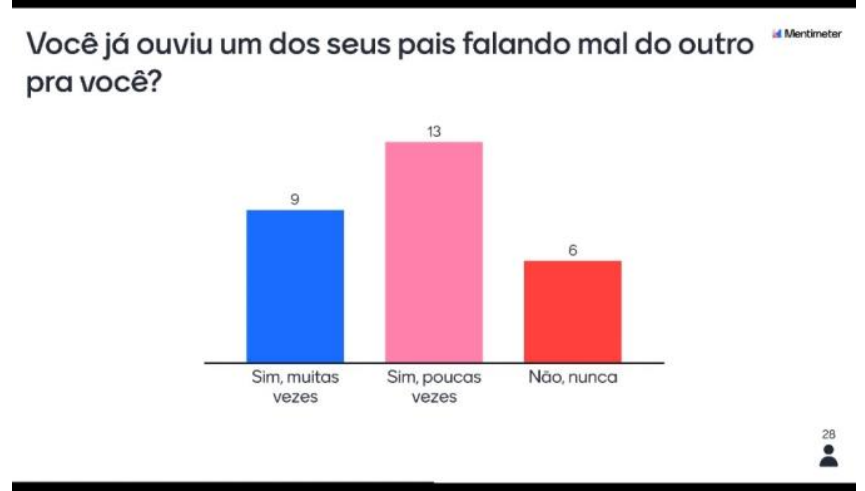

Fonte: (WAQUIM, 2020, p. 292).

A maioria dos participantes reportou a vivência da experiência de ouvir um dos genitores falando mal do outro em quantitativo que demonstra que essa é realidade inclusive quando os pais ainda estão em união conjugal. Na categoria "falar mal", inclui-se a previsão da Lei da Alienação Parental brasileira (n 12.318/2010) de realizar campanha de desqualificação da conduta do genitor no exercício da paternidade ou maternidade (artigo 2º, parágrafo único, inciso I).

Figura 4 - Relato sobre intimidades conjugais

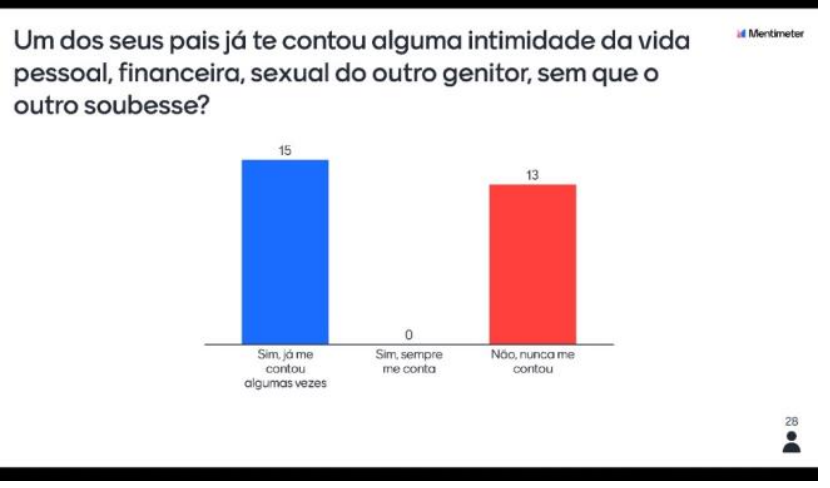

Fonte: (WAQUIM, 2020, p. 292).

Mais da metade dos participantes também reportaram ter sido depositários das intimidades conjugais dos seus genitores, recebendo confidências escondido do outro par, em número superior ao número de participantes cujos pais já se separaram/divorciando, 
mostrando, mais uma vez, a prática disseminada desse ato ainda na constância da relação conjugal.

Figura 5 - Participantes que possuem filhos

Você tem filhos?
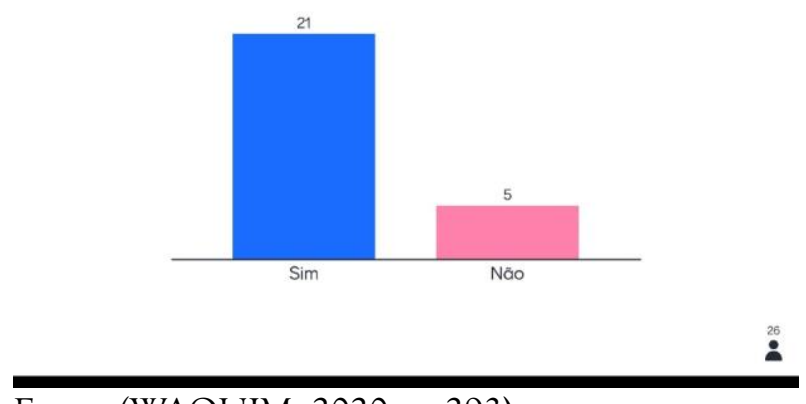

Fonte: (WAQUIM, 2020, p. 293).

Questionados se tinham filhos, 21 participantes responderam que sim. Essa pergunta teve por objetivo questionar, em uma plateia qualificada e buscando capacitação sobre o tema da Alienação Parental, quantos incorrem na naturalização de atos que reforçam a cultura de parentalidade tóxica, não saudável, o que foi objeto da última pergunta, descrita a seguir.

Figura 6 - Participantes que já falaram mal do outro genitor

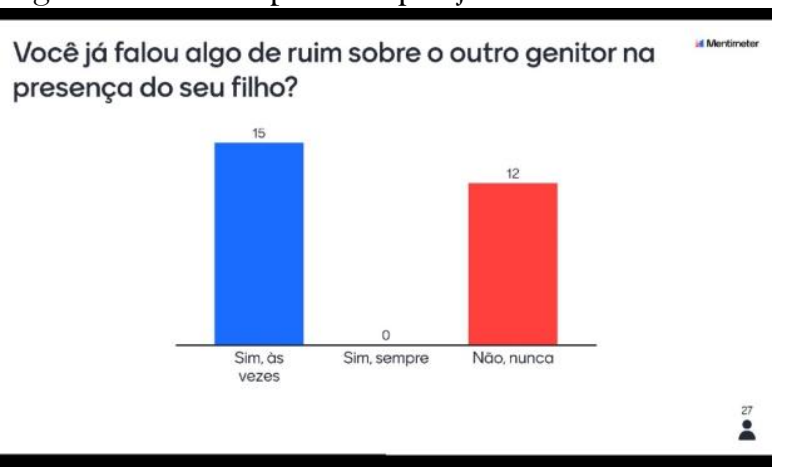

Fonte: (WAQUIM, 2020, p. 293).

Mais da metade dos participantes confidenciaram que, sendo eles próprios pais e mães, já praticaram o ato de "falar mal", característico da Alienação Familiar Induzida, em sua vertente da Alienação Parental Induzida. Isso acende o alerta sobre a necessidade de, efetivamente, se repensar a cultura do exercício da parentalidade, em busca de premissas mais saudáveis em prol da harmonia familiar e do respeito aos direitos dos filhos. Ainda que, em pequena amostragem, a referida pesquisa é elucidativa e ilustrativa sobre a cosmologia da violência da Alienação Parental. 
A noção de cosmologia refere-se ao modo por meio do qual os membros de uma determinada sociedade concebem seu universo e contemplam, nessa construção, suas reflexões sobre os outros e sobre si mesmos, incluindo, nesse processo de construção, as práticas do cotidiano (MIRAGLIA, 2007). Na cosmologia violenta da Alienação Parental, transfere-se intergeracionalmente um significado viciado e doentio sobre o exercício da conjugalidade e da parentalidade que constrói a comunidade-fantasma do sujeito filho e que repercutirá nos significantes relacionais que, enquanto adulto, vier a compor, reproduzindo o comportamento de violência psicológica contra parceiros e filhos.

Como se observa dos relatos acima, é costume dos genitores transbordar os conflitos conjugais para as relações de parentalidade e inserir os filhos no epicentro das angústias conjugais. A isso, Lisa Hooper atribuiu o nome de "parentification", algo como a inversão de papéis que inclui distorções de limites e uma hierarquia invertida entre pais e outros membros da família, na qual os jovens assumem atividades inadequadas de cuidado emocional e instrumental no sistema familiar que são prejudiciais ao seu desenvolvimento, atividades que não são reconhecidas, não são bem suportadas e não são recompensadas (HOOPER, 2007).

Crianças que experimentam parentalização/parentificação podem desempenhar uma série de funções: desde responder a necessidades emocionais dos pais ou irmãos (incluindo questões como baixa autoestima), a agir como pacificador da família (parentalidade emocional) e até mesmo assumir tarefas, como preparar refeições, fazer tarefas domésticas e lidar com questões financeiras (parentificação instrumental). Os efeitos da parentificação infantil podem ser duradouros e multigeracional e deletérios, produzindo consequências negativas que afetam não apenas o indivíduo, mas também a família, os cônjuges e possivelmente os filhos de adultos que foram parentificados. Para os jovens adultos, a parentalidade pode impedir o desenvolvimento normal relacionado à construção de relacionamento, à formação de personalidade e a outros processos críticos. Outros efeitos posteriores podem incluir doenças mentais em geral e depressão, ansiedade e transtornos por abuso de substâncias. O processo de parentificação infantil pode produzir adultos com medo de ter filhos e / ou levar à transmissão da parentificação ao longo de muitas gerações (HOOPER, 2007).

Ainda que estudos recentes possam evidenciar que tanto a parentificação quanto outros tipos de riscos infantis possam promover competências nas crianças, e não apenas as deficiências já esperadas, inspirando a resiliência nesse público (HOOPER, 2007), e que a parentificação instrumental seja menos lesiva que a parentificação emocional (HOOPER et al., 2011), muitos fatores podem contribuir para que esse mesmo evento ou processo leve a resultados divergentes. A parentificação pode ser percebida como traumática e estressante, 
ou como não traumática, ou como regular, e até mesmo como um evento cultural no decorrer do cotidiano. A literatura sobre trauma aponta que o número de estressores tem mais a ver com o resultado ou com a produção dos efeitos colaterais do que um determinado estressor em si (HOOPER, 2008).

Existem quatro formas mais comuns de violência intrafamiliar: física (quando alguém causa ou tenta causar dano por meio de força física, de algum tipo de arma ou instrumento que possa causar lesões internas, externas ou ambas); psicológica (toda ação ou omissão que causa ou visa a causar dano à autoestima, à identidade ou ao desenvolvimento da pessoa); negligência (a omissão de responsabilidade de um ou mais membros da família em relação a outro, sobretudo àqueles que precisam de ajuda por questões de idade ou alguma condição física, permanente ou temporária) e sexual (toda ação na qual uma pessoa, em situação de poder, obriga uma outra à realização de práticas sexuais, utilizando força física, influência psicológica ou uso de armas ou drogas) (DAY et al., 2003).

Discutir o problema da Alienação Familiar Induzida nas relações de família é reconhecer sua natureza de violência psicológica das crianças e dos adolescentes, vulnerabilizando todo o seu desenvolvimento psicossocial e representando verdadeira instalação de ciclos de parentalidade tóxica intergeracionais, podendo influenciar pessoas e a própria comunidade de entorno. Na lente proposta por Ceretti e Natali (2015), o processo aproxima-se da etapa da virulência, último estado do processo de violentização, com a consolidação do Self de "pessoa violenta" - ou, no caso, de genitor alienador ou filho alienado - a partir dos predicados conferidos pelos personagens das comunidades primárias e secundárias ao agente.

\section{CONSIDERAÇÕES FINAIS}

Discutir a violência no espaço da família soa contraditório, pois o ambiente familiar deveria ser o lugar do cuidado e da proteção de seus membros. De fato, a Constituição Federal, ao se referir à família, a nomina como "base da sociedade" (artigo 226), o que não a eleva a um pedestal alheio a regras de civilidade, ética e responsabilidade.

Embora a violência seja fenômeno observado ao longo da história, não se supõe aceitá-la como aspecto inevitável da condição humana (DAHLBERG; KRUG, 2006). Por isso, identificar novas formas de violência é um passo importante na discussão das relações humanas e na prevenção e no enfrentamento das situações de conflito.

O debate sobre a Alienação Parental é recente no Brasil. Em 2010, foi promulgada lei específica (Lei $n^{\circ} 12.318 / 2010$ ) e, mais recentemente, foi categorizada como violência psicológica (Lei no 13.431/2017), o que atraiu a atenção dos atores públicos e das 
instituições do Sistema da Justiça para a garantia dos interesses daqueles que são a maior vítima da prática da Alienação Parental: as crianças e os adolescentes, os quais, por estarem em peculiar processo de desenvolvimento humano, são mais vulneráveis emocional e psicologicamente.

Por isso, compreender o processo da prática do ato de Alienação Parental e os impactos que gera é central para que se interrompa o ciclo de violência intergeracional e se possa refletir sobre instrumentos de educação parental e empoderamento filial, a fim de que se evite a continuidade da naturalização dos atos de interferência familiar.

Pelo presente estudo, pôde-se estabelecer um paralelo entre as fases da violentização descritas por Ceretti e Lorenzo (2015) (inspirados pelo legado de Athens) e a prática de atos de Alienação Parental, em sua adequação terminológica de Alienação Familiar Induzida. Na fase de brutalização, identificou-se farta literatura da Psicologia, demonstrando o potencial que as famílias disfuncionais possuem em promover alinhamentos e alianças patológicas entre o familiar alienador (e, por conseguinte, psicológica e moralmente violento) com a criança ou adolescente vitimados pelos atos de alienação.

Correlacionou-se a fase seguinte da beligerância ao fenômeno característico da Alienação Parental descrito como "pensador independente", em que a comunidadefantasma do filho é contaminada de tal forma pelo comportamento violento do familiar alienador que lhe brutalizou que seu Self é manifestado como independente, embora tão somente reproduza a violência que lhe fora induzida.

Como ilustração à fase da atuação violenta, a pesquisa de campo sugeriu, ainda que por amostragem, como a oportunidade de praticar os atos violentos é internalizada no indivíduo, que reproduz, ainda que de forma inconsciente, práticas características de Alienação Familiar Induzida em seus relacionamentos da vida adulta, em virtude da naturalização dos comportamentos testemunhados enquanto filho.

Por fim, no estado de virulência, o abalo causado pela prática da Alienação Familiar Induzida demarca a família como espaço de dissensões, conflitos de lealdade e a posição de alienadores e alienados, não raro causando verdadeiro fogo cruzado entre os familiares na prática dos atos de alienação.

Sem qualquer pretensão de conclusões definitivas, sugerimos abrir o debate sobre a interlocução proposta e problematizar a Alienação Parental como fenômeno violento, que possui notas peculiares em sua cosmologia que agregam repercussões ao desenvolvimento infantojuvenil. 


\section{REFERÊNCIAS}

AKERS, Ronald. Deviant behavior: a social learning approach. Wadsworth: Wadsworth Pub Co, 1977.

ANITUA, Gabriel Ignacio. Historia de los pensamientos criminológicos. Buenos Aires: Del Puerto, 2005.

ARAUJO, Sandra Maria Baccara. O genitor alienador e as falsas acusações de abuso sexual. In: DIAS, Maria Berenice (coord.). Incesto e alienação parental: de acordo com a Lei 12.318/2010. 4. ed. São Paulo: Revista dos Tribunais, 2017.

ATHENS, Lonnie H. (ed.) Radical Interactionism on the Rise. Studies in Symbolic Interaction. Bingley: Emerald Group Publishing, 2013.

ATHENS, Lonnie H. The Creation of Dangerous Violent Criminals. Urbana: University of Illinois Press, 1992.

BAKER, Amy J. L. Patterns of Parental Alienation Syndrome: A Qualitative Study of Adults Who were Alienated from a Parent as a Child. The American Journal of Family Therapy. Volume 34, 2006. Disponível em: https://www.tandfonline.com/doi/abs/10.1080/01926 180500301444. Acesso em: 17 jun. 2019.

BAKER, Amy J. L.; DARNALL, Douglas. Behaviors and Strategies Employed in Parental Alienation: A Survey of Parental Experiences. Journal of Divorce \& Remarriage, v. 45, n. 1/2, 2006. Disponível em: https://www.researchgate.net/publication/233228321_Behavi ors_and_Strategies_Employed_in_Parental_Alienation. Acesso em: 19 jun. 2020.

BEN-AMI, Naomi; BAKER, Amy J. L. The Long-Term Correlates of Childhood Exposure to Parental Alienation on Adult Self-Sufficiency and Well-Being. The American Journal of Family Therapy, v. 40, n. 2, 2012. Disponível em: https://www.tandfonline.com/doi/full/ 10.1080/01926187.2011.601206? src=recsys. Acesso em: 28 jun. 2020

BLUMER, H. Symbolic Interationism. Perspective and Method. Berkley: University of California Press, 1969.

BORACS, Rahel. Narcisismo - Autoestima, identidade, alteridade. Revista Brasileira de Psiquiatria, v. 32, n. 2. Jun. 2010. Disponível em: https://www.scielo.br/j/rbp/a/CMyz BrpGNwyTDDWmNvc3ksH/?format=pdf\&lang=pt. Acesso em: 20 jun. 2020. 
CALÇADA, Andreia. Falsas acusações de abuso sexual: para entender e intervir. In: ANDRADE, Murillo; RICARDO, Rodrigo (org.). Alienação parental: VI Congresso Nacional e IV Congresso Internacional. Belo Horizonte: Poesias Escolhidas, 2017.

CARVALHO, Virgínia Donizete de. Interacionismo Simbólico: origens, pressupostos e contribuições aos estudos organizacionais. Administração: Ensino e Pesquisa, Rio de Janeiro. v. 12. n. 4. p. 583-607, out./nov./dez. 2011. Disponível em: https://www.researchgate.net/publication/276459790_INTERACIONISMO_SIMBOLIC O_ORIGENS_PRESSUPOSTOS_E_CONTRIBUICOES_AOS_ESTUDOS_ORGANIZA CIONAIS. Acesso em: 26 jul. 2020.

CARVALHO, Virgínia Donizete de; BORGES, Livia de Oliveira; REGO, Denise Pereira do. Interacionismo simbólico: origens, pressupostos e contribuições aos estudos em Psicologia Social. Psicol. cienc. prof., Brasília, v. 30, n. 1, p. 146-161, mar. 2010. Disponível em http://pepsic.bvsalud.org/scielo.php?script=sci_arttext\&pid=S1414-9893201000010001 $1 \& \operatorname{lng}=\mathrm{pt} \& \mathrm{nrm}=\mathrm{iso}$. Acesso em: 29 fev. 2020.

CERETTI, Adolfo; LORENZO, Natali. Cosmologias violentas: itinerários criminológicos. Barcelona: Marcial Pons, 2015.

COELHO, Maria Isabel Saldanha dos Martins; MORAIS, Normanda Araujo de. Contribuições da Teoria Sistêmica acerca da Alienação Parental. Contextos Clínic, São Leopoldo, v. 7, n. 2, p. 168-181, dez. 2014. Disponível em http://pepsic.bvsalud.org/scielo.php?script=sci_arttext\&pid=S1983-34822014000200006\& lng=pt\&nrm=iso. Acesso em: 4 jan. 2021. http://dx.doi.org/10.4013/ctc.2014.72.05.

DAHLBERG, Linda L.; KRUG, Etienne G. Violência: um problema global de saúde pública. Ciênc. saúde coletiva, Rio de Janeiro, v. 11, p. 1163-1178, 2006. Disponível em: http://www.scielo.br/scielo.php?script=sci_arttext\& $\mathbf{p i d}=\mathbf{S} 1413-81232006000500007 \& \ln g$ $=e n \&$ nrm=iso. Acesso em: 26 jul. 2020.

DAY, Vivian Peres et al. Violência doméstica e suas diferentes manifestações. R. Psiquiatr. RS, v. 25, n. 1, p. 9-21, abr. 2003. Disponível em: https://www.researchgate.net/publication/26357396_Violencia_domestica_e_suas_diferen tes_manifestacoes/fulltext/0e605334f0c46d4f0aafdf9c/Violencia-domestica-e-suasdiferentes-manifestacoes.pdf. Acesso em: 26 jul. 2020.

DIAS, Maria Berenice. Alienação parental: realidade difícil de ser reconhecida. In: DIAS, Maria Berenice (coord.). Incesto e alienação parental: de acordo com a Lei 12.318/2010. 4. ed. São Paulo: Revista dos Tribunais, 2017. 
EYSENCK, H. J. Personality theory and the problem of criminality. In: MCLAUGHLIN, E.; MUNCIE, J.; HUGHES, G. Criminological perspectives: essential readings. Londres: Sage, 1993. p. 91-109.

GARDNER, Richard A. Guidelines for Assessing Parental Preference in Child-Custody Disputes. Journal of Divorce \& Remarriage, v. 30, n. 1/2, p. 1-9, 1999. Disponível em: https://www.tandfonline.com/doi/abs/10.1300/J087v30n01_01. Acesso em: 21 jan. 2019.

GARDNER, Richard A. Parental Alienation Syndrome vs. Parental Alienation: Which Diagnosis Should Evaluators Use in Child-Custody Disputes? The American Journal of Family Therapy, v. 30, p. 93-115, 2002. Disponivel em: https://www.researchgate.net/publication/247510295_Parental_Alienation_Syndrome_vs_ Parental_Alienation_Which_Diagnosis_Should_Evaluators_Use_in_Child-Custody_Dispu tes. Acesso em: 21 jan. 2019.

HOOPER, Lisa M. The Application of Attachment Theory and Family Systems Theory to the Phenomena of Parentification. The Family Journal, v. 15, n. 3, p. 217, 2007. Disponível em: http://tfj.sagepub.com/cgi/content/abstract/15/3/217. Acesso em: 16 jul. 2020.

HOOPER, Lisa M. et al. The Parentification Inventory: Development, Validation, and Cross-Validation. The American Journal of Family Therapy, v. 39, n. 3, p. 226-241, 2011. Disponível em: https://doi.org/10.1080/01926187.2010.531652. Acesso em: 16 jul. 2020.

HOOPER, Lisa M. Defining and Understanding Parentification: Implications for All Counselors. The Alabama Counseling Association Journal, v. 34, n. 1, 2008. Disponível em: https://www.researchgate.net/publication/281905738_Defining_and_Understanding _Parentification_Implications_for_All_Counselors. Acesso em: 25 jun. 2020.

JALAVA, Jarkko. The modern degenerate: nineteenth-century Degeneration Theory and Modern Psychopathy Research. Theory \& Psychology, v. 16, n. 3, p. 416-432, 2006.

MACHADO, Bruno Amaral. Discursos criminológicos sobre o crime e o direito penal: comunicação e diferenciação funcional. Revista de Estudos Criminais, n. 45, p. 77-116, abr./jun. 2012.

MEAD, George. Espíritu, persona y sociedad: desde el punto de vida del conductismo social. Barcelona: Paidós Ibérica, 1973.

MIRAGLIA, Paula. Cosmologias da Violência: entre a regra e a exceção. Uma etnografia da desigualdade em São Paulo. 2007. 225 f. Tese (Programa de Pós-Graduação em Antropologia Socia) - Universidade de São Paulo, São Paulo, 2007. 
MOLD, Cristian Fetter. Alienação parental recíproca. In: DIAS, Maria Berenice (coord.). Incesto e alienação parental: de acordo com a Lei 12.318/2010. 4. ed. São Paulo: Revista dos Tribunais, 2017.

MONTAÑO, Carlos. Alienação parental e guarda compartilhada: um desafio ao serviço social na proteção dos mais indefesos: a criança alienada. Rio de Janeiro: LumenJuris, 2016.

MOREIRA, Luciana Maria Reis. Alienação parental. Belo Horizonte: D’Plácido, 2016.

PORTO, Maria Stela Grossi. A violência urbana e suas representações sociais: o caso do Distrito Federal. São Paulo Perspectiva, São Paulo, v. 13 n. 4, out./dez. 1999.

ROSENFELD, Rogério. A Cosmologia. Física na Escola, v. 6, n. 1, 2005. Disponível em: http://www.sbfisica.org.br/fne/Vol6/Num1/cosmologia.pdf. Acesso em: 21 jun. 2020.

SAMPSON, Robert J. Great American City: Chicago and the enduring neighborhood effect. Chicago: University of Chicago Press, 2012.

SARNOFF, A. Mednick; GABRIELLI, William F.; HUTCHINGS, Barry. Genetic factors in the etiology of criminal behavior. In: Mclaughlin, E.; MUNCIE, J; HUGHES, G. Criminological Perspectives: essential readings. Londres: Sage, 1993. p. 77-90.

SILVA, Luciane Lemos da et al. Violência silenciosa: violência psicológica como condição da violência física doméstica. Interface (Botucatu), v. 11, n. 21, abr. 2007. Disponível em: https://www.scielo.br/j/icse/a/9SG5zGMVt4VFDZtzbX97MkP/?lang=pt. Acesso em: 28 jun. 2020.

SILVA, Luis Antonio Machado. Sociabilidade violenta: por uma interpretação da criminalidade contemporânea no Brasil urbano. Sociedade e Estado, v. 19, n. 1, p. 53-84, 2004.

SIMON, Johnatan. Managing the monsters: Sex Offenders and the New Penology. Psychology Public Policy and Law, v. 4, n. 1-2, p. 452-467, 1998.

SACRAMENTO, Lívia de Tartari; REZENDE, Manuel Morgado. Violências: lembrando alguns conceitos. Aletheia, n. 24, p. 95-104, 2006. Disponível em: http://pepsic.bvsalud.org/scielo.php?pid=S1413-03942006000300009\&script=sci_abstract. Acesso em: 28 jun. 2020. 
VERROCCHIO, M. C. et al. Depression and quality of life in adults perceiving exposure to parental alienation behaviors. Health Qual Life Outcomes, v. 17, n. 14, 2019. Disponível em: https://www.ncbi.nlm.nih.gov/pmc/articles/PMC6332910/. Acesso em: 28 jun. 2020.

VIOLÊNCIA: definições e tipologias [recurso eletrônico] / Universidade Federal de Santa Catarina; organizadores, Elza Berger Salema Coelho, Anne Carolina Luz Grüdtner Silva, Sheila Rubia Lindner. Florianópolis: Universidade Federal de Santa Catarina, 2014. Disponível em: https://ares.unasus.gov.br/acervo/html/ARES/1862/1/Definicoes_Tipolo gias.pdf. Acesso em: 28 jun. 2020.

WALBY, Kevin; CARRIER, Nicolas. The rise of biocriminology: Capturing observables bodily economies of "criminal man". Criminology and Criminal Justice, v. 10, p. 261-285, 2010.

WAQUIM, Bruna Barbieri. Alienação familiar induzida: aprofundando o estudo da Alienação Parental. 2. ed. Rio de Janeiro: Lumen Juris, 2018.

WAQUIM, Bruna Barbieri. A integração da Alienação Parental à Doutrina da Proteção Integral: repercussões jurídico-políticas do enquadramento da Alienação Familiar Induzida como situação de risco. 2020. 402 f. Tese (Programa de Pós-Graduação Stricto Sensu em Direito) -Centro Universitário de Brasília - UniCEUB, Brasília, 2020.

\section{NOTA}

Em atenção ao artigo "A ALIENAÇÃO PARENTAL COMO COSMOLOGIA VIOLENTA", aceito para publicação na Revista Opinião, de nossa autoria conjunta, declaramos: O presente artigo foi inspirado na Disciplina "Violências: debate teórico, políticas públicas e estratégias de prevenção" ministrada pelo Prof. Bruno Amaral Machado junto ao Doutorado em Direito do CEUB, tendo o esboço do presente artigo sido apresentado como trabalho final da Disciplina (em junho de 2020). Após a conclusão do Doutorado (em agosto de 2020), convidei o Prof. Bruno a revisar o artigo e aperfeiçoá-lo, visando a sua publicação na Revista Opinião Jurídica, gerando o produto final submetido em fevereiro de 2021 e que foi acolhido por esta Equipe Editorial.

\section{Como citar este documento:}

WAQUIM, Bruna Barbieri; MACHADO, Bruno Amaral. A alienação parental como cosmologia violenta. Revista Opinião Jurídica, Fortaleza, v. 19, n. 32, p. 202-227, set./dez. 2021. 